\title{
POTENSI LESTARI IKAN LAYANG (Decapterus spp) BERDASARKAN HASIL TANGKAPAN PUKAT CINCIN DI PERAIRAN TIMUR SULAWESI TENGGARA
}

\author{
THE SUSTAINABLE YIELD POTENTIAL (Decapterus spp) ON THE BASIS OF THE \\ CATCH PURSE SEINE IN THE WATERS OF THE EAST SOUTHEAST SULAWESI
}

\author{
Amir Mahmud ${ }^{1}$, Rita .L. Bubun ${ }^{1}$ \\ ${ }^{1}$ Program Studi Pemanfaatan Sumberdaya Perikanan \\ Fakultas Perikanan dan Ilmu Kelautan, Universitas Muhammadiyah Kendari \\ Korespondensi : rl.bubun@gmail.com
}

\begin{abstract}
Decapterus spp is one of small pelagic fish species having potential and high economic value in Southeast Sulawesi. The utilization of resources activities in East Southeast Sulawesi is using the purse seine units. Study aim was to determine of the maximum sustainable yield (MSY) and catches of the Decapterus spp allowed (JTB) in the East Southeast Sulawesi waters. This research was using survey method to get a represented potential of Decapterus spp in the East Southeast Sulawesi waters. The approach done by means of analyzed data efforts and the catch data of Decapterus spp by using the purse seine unit in Pelabuhan Perikanan Samudera Kendari. The results about the potential fish a sustainable (Decapterus $s p p$ ) were : the maximum sustainable yield (MSY) of Decapterus spp: 5.747.61tonnes/years and catches of Decapterus spp allowed (JTB) 4.598 tonnes/ year.
\end{abstract}

Keywords: Decapterus spp, maximum sustainable yield, purse seine, Southeast Sulawesi

\begin{abstract}
ABSTRAK
Ikan layang (Decapterus spp) merupakan salah satu sumberdaya ikan ikan pelagis kecil yang memiliki potensi dan nilai ekonomis tinggi di Sulawesi Tenggara. Kegiatan pemanfaatan sumberdaya ikan layang di Sulawesi Tenggara umumnya dilakukan oleh unit penangkapan ikan purse seine (pukat cincin). Tujuan kajian ini yaitu menentukan potensi maksimum lestari (MSY) dan jumlah tangkapan ikan layang yang diperbolehkan (JTB) di perairan bagian Timur Sulawesi Tenggara. Penelitian ini menggunakan metode survei untuk mendapatkan gambaran yang dapat mewakili potensi ikan layang di perairan Timur Sulawesi Tenggara. Pendekatan dilakukan dengan cara menganalisis data upaya penangkapan dan data hasil tangkapan (produksi) ikan layang oleh unit penangkapan pukat cincin yang didaratkan di Pelabuhan Perikanan Samudera (PPS) Kendari. Hasil penelitian menunjukkan MSY ikan layang sebesar 5.747.61 ton/tahun dan jumlah JTB sebesar 4.598 ton/tahun.
\end{abstract}

Kata kunci: ikan layang, potensi lestari, pukat cincin, Sulawesi Tenggara 


\section{PENDAHULUAN}

Pengetahuan mengenai sumberdaya ikan dan kemampuan yang memadai dari sumberdaya manusia merupakan salah satu syarat penentu keberhasilan pengelolaan perikanan (Widodo \& Suadi 2006). Langkah awal yang perlu dilakukan adalah mengetahui potensi sumberdaya ikan di suatu perairan laut melalui suatu analisis. Hal tersebut penting untuk mengontrol kegiatan penangkapan ikan sehingga dapat mencegah eksploitasi berlebihan yang dapat merusak kelestarian sumberdaya ikan. Analisis potensi ikan dimaksudkan untuk menghasilkan informasi tentang kelimpahan stok ikan di suatu perairan, rekomendasi jumlah upaya penangkapan optimum, dan jumlah tangkapan ikan yang diperbolehkan. Ikan layang (Decapterus spp) merupakan salah satu sumberdaya ikan pelagis kecil yang memiliki potensi dan nilai ekonomis tinggi di Sulawesi Tenggara. Kegiatan pemanfaatan sumberdaya ikan layang di Sulawesi Tenggara umumnya dilakukan oleh unit penangkapan ikan purse seine (pukat cincin). Beberapa daerah penangkapan ikan layang di Sulawesi Tenggara adalah di Perairan Menui, Perairan Saponda, dan Perairan Wawonii (Selanjutnya disebut "Perairan Timur Laut Sulawesi Tenggara"). Produksi ikan layang dari perairan tersebut terekam dalam catatan Statistik Perikanan Kota Kendari (termasuk PPS Kendari), Kabupaten Konawe, dan Konawe Utara.

Data Dinas Kelautan dan Perikanan Provinsi Sulawesi Tenggara dari tahun 20072011 , rata-rata $69.50 \%$ dari total produksi ikan layang di tiga Kabupaten/Kota (Kota Kendari, Kabupaten Konawe, dan Konawe Utara) didaratkan di PPS Kendari. Oleh karena itu, lokasi pengumpulan data dalam penelitian ini dilakukan di PPS Kendari.

Penerapan aturan kegiatan penangkapan ikan layang di perairan timur Laut Sulawesi Tenggara yang belum dilaksanakan secara maksimal, disebabkan oleh informasi mengenai tingkat pemanfaatan ikan layang belum tersedia. Apabila kondisi ini tidak mendapat perhatian dan pengelolaan secara bijak, maka dapat memicu eksploitasi penangkapan yang melebihi potensi maksimum lestari ikan layang. Berdasarkan hal tersebut, maka tujuan dari kajian ini yaitu menentukan potensi maksimum lestari (MSY) dan jumlah tangkapan ikan layang yang diperbolehkan (JTB) di Perairan bagian Timur Sulawesi Tenggara.

\section{METODE PENELITIAN}

Penelitian ini dilaksanakan selama 5 bulan dari Bulan Juni-Oktober 2015. Pelaksanaan penelitian berlokasi di Pelabuhan Perikanan Samudera (PPS) Kendari sebagai pangkalan perikanan pukat cincin yang menangkap ikan layang di perairan timur laut Sulawesi Tenggara.

Penelitian ini menggunakan metode survei untuk mendapatkan gambaran yang dapat mewakili potensi dan tingkat pemanfaatan ikan layang di perairan timur laut Sulawesi Tenggara. Pendekatan dilakukan dengan cara menganalisis data upaya penangkapan dan data hasil tangkapan (produksi) ikan layang oleh unit penangkapan pukat cincin yang di daratkan di PPS Kendari.

Data yang dikumpulkan dalam penelitian yaitu data primer dan data sekunder. Data primer melalui kuesioner dan wawancara untuk memperoleh informasi tentang kondisi umum PPS Kendari dan usaha perikanan pukat cincin yang berpangkalan di PPS Kendari. Data sekunder diperoleh dari Kantor Pusat PPS Kendari, yang meliputi data daerah penangkapan, operasi penangkapan ikan (jumlah trip operasi, hasil tangkapan per trip, jumlah kapal, dan tempat pemberangkatan) selama tujuh tahun terakhir, yaitu dari Tahun 2007-2013. Penelitian ini menggunakan data tahunan hasil tangkapan ikan layang yang di daratkan di PPS Kendari (satuan: ton/tahun). Adapun jumlah upaya penangkapan pukat cincin yang beroperasi sama dengan banyaknya trip penangkapan pada suatu periode tahun.

\section{Analisis Data}

Analisis data yang digunakan dalam penelitian ini adalah metode produksi surplus (model Schaefer). Model tersebut digunakan untuk menghitung nilai MSY. Setelah MSY diketahui, selanjutnya dapat dihitung JTB. Data yang akan digunakan adalah data upaya penangkapan alat tangkap purse seine dan hasil tangkapan ikan layang yang didaratkan di PPS Kendari.

Analisis hasil tangkapan per upaya
penangkapan (CPUE)
Hasil tangkapan per upaya
penangkapan dapat dihitung berdasarkan
pembagian jumlah hasil tangkapan dengan
upaya penangkapan. Formula yang
digunakan (Gulland 1983) yaitu:

Analisis hasil tangkapan per upaya Hasil tangkapan per upaya gapan dengan yang digunakan (Gulland 1983) yaitu: 


$$
\mathrm{CPUE}_{\mathrm{i}}=\frac{c i}{f i}
$$

keterangan:

CPUE = Hasil tangkapan per upaya penangkapan tahun ke I (ton/trip)

$i \quad=1,2,3, \ldots, \mathrm{n}$

$c i \quad=$ Hasil tangkapan tahun ke-I (ton)

fi = Upaya penangkapan tahun ke-I (trip)

Analisis potensi sumberdaya ikan layang

Data yang dianalisis meliputi jumlah trip operasi penangkapan dengan alat tangkap yang menangkap ikan layang dan jumlah ikan hasil tangkapan alat tersebut. Perhitungananalisis sumberdayaikanlayang dilakukan dengan menggunakan model Schaefer. Caranya dengan menghubungkan upaya penangkapan (effort) dan CPUE alat tangkap ikan layang.

Hubungan antara upaya penangkapan dan CPUE alat tangkap diperoleh dengan menggunakan analisis kuadrat terkecil, yaitu dengan cara meminimumkan simpangan. Hubungan fungsi tersebut dapat ditunjukan dengan persamaan berikut (Schaefer vide Sparre \& Venema 1999):

$$
\mathrm{Y}=a+\beta X+e
$$

keterangan:

$\mathrm{Y}=$ peubah tak bebas (nilai CPUE) (ton/ trip)

$X$ = upaya penangkapan, sebagai peubah bebas dalam satuan trip operasi penangkapan jenis alat tangkap standar untuk menangkap ikan tertentu

$a, \beta=$ parameter regresi penduga nilai a dan b

$e=$ simpangan

Kemudian diduga dengan fungsi dugaan yaitu:

sehingga,

$$
\hat{\mathrm{Y}}=a+b x
$$

$$
\begin{aligned}
\mathrm{e} & =Y-\hat{Y} \\
\Sigma \mathrm{e} 2 & =(Y-\hat{Y})^{2}
\end{aligned}
$$

Setelah itu, dengan analisis kuadrat terkecil nilai $\sum \mathrm{e} 2$ diminimumkan. Nilai e akan minimum bila turunan pertama fungsi sama dengan nol, sehingga nilai dugaan dapat diperoleh sebesar a dan b. Nilai a dan b dapat ditentukan sebagai berikut:

$$
\begin{gathered}
\mathrm{a}=\frac{\left(\sum y_{i}-b \sum x_{i}\right)}{n} \\
\mathrm{~b}=\frac{n \sum x_{i} y_{i}-\sum x_{i} \sum y_{i}}{n \sum x i^{2}-\left(\sum x_{i}\right)^{2}}
\end{gathered}
$$

keterangan:

$\mathrm{a}=$ Intersep (titik perpotongan garis regresi dengan sumbu y)

$\mathrm{b}=$ Slop (kemiringan) dari garis regresi .

Dari persamaan-persamaan di atas, dapat dicari nilai-nilai sebagai berikut:

Hubungan antara CPUE dan upaya penangkapan (f):

$$
\mathrm{CPUE}=a-b f
$$

Hubungan antara hasil tangkapan (c) dan upaya penangkapan (f):

$$
\mathrm{c}=a f-b f^{2}
$$

Upaya penangkapan optimum (fopt) diperoleh dengan cara menyamakan turunan pertama hasil tangkapan terhadap upaya penangkapan sama dengan nol:

$$
\begin{gathered}
\mathrm{c}=a f-b f^{2} \\
c^{\prime}=\mathrm{a}-2 \mathrm{bf}=0 \\
\mathrm{f}_{\mathrm{opt}}=-\frac{a}{2 b}
\end{gathered}
$$

Potensi maksimum lestari (MSY) diperoleh dengan mensubtitusikan nilai upaya penangkapan optimum kedalam formula :

$$
\begin{gathered}
\mathrm{c}_{\text {maks }}=a\left(\frac{a^{2}}{b}\right)-b\left(\frac{a^{2}}{4 b^{2}}\right) \\
\mathrm{MSY}=-\frac{a^{2}}{4 b}
\end{gathered}
$$

CPUE optimum dapat dihitung berdasarkan formula:

$$
\mathrm{CPUE}_{\text {opt }}=\frac{M S Y}{f_{\text {opt }}}
$$

Analisis jumlah tangkapan yang diperbolehkan (JTB)

Setyohadi (2009) menyatakan bahwa jumlah tangkapan yang diperbolehkan (JTB) adalah 80\% dari potensi lestari. Oleh karena itu, JTB dapat dihitung dengan menggunakan formula sebagai berikut:

$$
\mathrm{JTB}=\operatorname{MSY} \times 80 \%
$$




\section{HASIL DAN PEMBAHASAN}

\section{Hasil penelitian}

\section{Unit penangkapan ikan pukat cincin}

Unit penangkapan ikan pukat cincin yang beroperasi di perairan bagian timur Sulawesi Tenggara terdiri dari berbagai ukuran. Ukuran kapal antara 5-50 GT. Jumlah unit penangkapan ikan pukat cincin pada Tahun 2007-2013 sangat fluktuatif. Data ukuran dan jumlah kapal unit penangkapan pukat cincin dapat dilihat pada Tabel 1.

\section{Daerah penangkapan ikan layang}

Hasil observasi daerah penangkapan ikan layang berada pada Wilayah Pengelolaan Perikanan (WPP) 714 Laut Banda. Koordinat operasi penangkapan ikan kapal pukat cincin berada pada 3 $52 ' 27^{\prime \prime}-3^{\circ} 58 ' 56^{\prime \prime}$ Lintang Selatan dan $122^{\circ} 50^{\prime} 48^{\prime \prime}-122^{\circ} 58^{\prime} 27^{\prime \prime}$ Bujur Timur. Suhu permukaan laut (SPL) berkisar antara 28 ${ }^{\circ} \mathrm{C}-30{ }^{\circ} \mathrm{C}$. Salintas perairan berkisar antara $32 \%$ - 33\%o. Lokasi observasi dapat dilihat pada Gambar 1.

\section{Musim penangkapan ikan layang}

Musim penangkapan ikan layang di perairan bagian timur Sulawesi Tenggara berdasarkan hasil analisis volume produksi hasil tangkapan ikan layang dari bulan Januari-Desember pada ukuran 5-30 GT. Volume produksi ikan layang tertinggi terjadi pada bulan Januari yaitu 107.691 ton. Musim penangkapan ikan layang berdasarkan volume produksi dapat dilihat pada Gambar 2 .

\section{Produksi dan poduktivitas hasil tangkapan} ikan layang

Produksi hasil tangkapan ikan layang di perairan bagian timur Sulawesi Tenggara pada tahun 2007-2013 berfluktuasi. Hal ini sehubungan dengan upaya penangkapan (trip) yang fluktuatif. Produksi hasil tangkapan ikan tertinggi pada tahun 2007 yaitu 6.763 ton dengan upaya penangkapan sebanyak 2.996 trip. Produksi hasil tangkapan ikan terendah pada tahun 2008 yaitu 2.313 ton dengan upaya penangkapan sebanyak 2.574 trip. Hubungan antara besarnya produksi hasil tangkapan ikan dengan upaya penangkapan yang dilakukan dalam satuan trip penangkapan, berpengaruh secara fluktuatif terhadap produktivitas hasil tangkapan (CPUE). Produksi dan produktivitas hasil tangkapan ikan layang akan meningkat apabila upaya penangkapan ikan (trip) dapat dikurangi. Produksi hasil tangkapan, upaya penangkapan dan produktivitas hasil tangkapan dapat dilihat pada Gambar 3 .

Potensi maksimum lestari (MSY) dan jumlah tangkapan ikan layang yang diperbolehkan (JTB)

Hasil analisis terhadap produksi hasil tangkapan ikan layang pada Tahun 20072013, diperoleh MSY ikan layang di perairan bagian timur Sulawesi Tenggara sebesar 5.748 ton/tahun. JTB untuk dieksploitasi sebesar 4.598 ton/tahun. Besarnya produksi, MSY dan JTB ikan layang dapat dilihat pada Gambar 4.

Tahun 2013 yaitu 6.412 ton. Produksi tersebut telah melebihi potensi MSY dan JTB yang diperbolehkan untuk dieksploitasi.

\section{Pembahasan}

Unit penangkapan ikan pukat cincin

Pukat cincin yang dikenal dengan nama lokal kapal "gae" mempunyai peran penting dalam pemanfaatan sumberdaya perikanan di Sulawesi Tenggara. Ukuran pukat cincin yang dioperasikan beragam. Pada kapal pukat cincin yang berukuran 27 GT memiliki panjang jaring $500 \mathrm{~m}$, kedalaman jaring $90 \mathrm{~m}$, ukuran mata jaring $2 \mathrm{~cm}$ dan jumlah ABK dalam satu unit penangkapan pukat cincin sebanyak 25 orang. Fluktuasi jumlah unit penangkapan ikan pukat cincin dari tahun 2007-2013 di dominasi oleh armada yang berukuran 5-10 GT. PERMEN No. 2 Tahun 2011 menjelaskan bahwa armada penangkapan ikan yang berukuran 5-10 GT dapat dioperasikan pada perairan yang berjarak 2-4 mil laut. Fluktuasi jumlah unit penangkapan ikan dari berbagai ukuran disebabkan kapal pukat cincin yang mendaratkan hasil tangkapannya di Pelabuhan Perikanan Samudera (PPS) Kendari terdiri dari kapal pukat cincin lokal dan kapal pukat cincin pendatang. Kapal pukat cincin pendatang berasal dari Sulawesi Selatan yang dikenal masyarakat nelayan setempat dengan kapal putih.

Kapal pukat cincin pendatang melakukan pendaratan hasil tangkapan 
di PPS Kendari pada saat harga ikan lebih tinggi daripada daerah asalnya, dan tidak mendaratkan hasil tangkapannya di PPS Kendari apabila harga ikan lebih rendah. Kapal pukat pendatang tersebut mendaratkan hasil tangkapannya di tempat-tempat pendaratan ikan yang hasil penjualannya lebih menguntungkan. Kondisi ini menyebabkan jumlah unit penangkapan ikan setiap tahun tidak tetap. Hal ini berdampak pada jumlah upaya penangkapan (trip penangkapan) pukat cincin.

\section{Daerah penangkapan ikan layang}

Distribusi ikan layang dapat ditemukan di seluruh perairan dunia. Dapat tersebar pada perairan tropis dan subtropis di IndoPasifik dan Lautan Atlantik (Simbolon 2011). Daerah penangkapan ikan layang di Indonesia dapat ditemukan di Laut Banda pada $100 \mathrm{~m}$.

Salinitas perairan yang disenangi oleh ikan layang berkisar antara 30\%-34\%o. Suhu perairan memiliki peranan penting bagi penyebaran ikan layang. Suhu perairan untuk ikan layang berkisar antara $20^{\circ} \mathrm{C}-30$ ${ }^{\circ} \mathrm{C}$ (Nontji 2002).

Hasil observasi pada tiga koordinat daerah penangkapan ikan layang terletak pada WPP 714 Laut Banda. Kondisi daerah penangkapan ikan yaitu suhu permukaan laut (SPL) berkisar antara $28{ }^{\circ} \mathrm{C}-30 \quad{ }^{\circ} \mathrm{C}$ dan salintas perairan berkisar antara 32\%o-33\%. Kondisi oseanografi perairan ini sesuai dengan habitat ikan layang deles (Decapterus macrosoma). Daerah penangkapan ikan layang yang didaratkan di PPS Kendari berasal dari Perairan Utara Wawonii, Perairan Menui dan Perairan Saponda.

\section{Musim penangkapan ikan layang}

Ikan layang dapat ditemukan sepanjang tahun di Selat Sunda, Selat Makassar, Teluk Ambon, Teluk Kupang, Sulawesi Tenggara dan Teluk Tomini. Musim penangkapan ikan di Perairan Sulawesi Tenggara dapat ditemukan pada bulan Januari-April dan bulan Juli-September (Simbolon 2011).

Hasil analisis musim penangkapan ikan layang di Perairan Sulawesi Tenggara pada Tahun 2007-2013, diperoleh informasi bahwa musim puncak penangkapan ikan layang terjadi pada bulan Januari-Juni. Kondisi ini dapat dilihat berdasarkan volume hasil tangkapan ikan layang selama bulan Januari-Juni (Gambar 4). Volume hasil tangkapan mulai menurun pada bulan Jul-Desember.

Musim penangkapan ikan layang sangat dipengaruhi dengan salinitas perairan sebagai habitat spesies tersebut. Berdasarkan hasil observasi yang dilakukan selama bulan Mei-Juli diketahui salinitas perairan berkisar antara 32\%o-33\%o. Simbolon (2011) menjelaskan bahwa pada musim timur (Juni-September), massa air massa bersalinitas tinggi yang berasal dari Laut Flores dan Samudera Pasifik mengalir melalui Selat Makassar menuju ke Laut Jawa. Pada musim barat (Desember-Maret) arus permukaan bergerak dari Laut Cina Selatan (Natuna) memasuki Laut Jawa dari arah barat ke arah timur. Pergerakan arus ini membawa massa air laut dengan salinitas tinggi.

Perairan Wawoni dan Perairan Saponda sebagai lokasi penelitian terletak di Laut Banda. Perairan ini pada musim timur memiliki salinitas perairan yang tinggi berasal dari Samudera Pasifik. Pergerakan massa air yang bersalinitas tinggi diikuti oleh migrasi ikan layang. Hal ini menyebabkan pada bulan Januari-Juni merupakan musim ikan layang di sekitar perairan Laut Banda termasuk perairan timur Sulawesi Tenggara.

\section{Produksi dan produktivitas hasil tangkapan ikan layang}

Hasil tangkapan ikan layang sebagai produksi dari operasi penangkapan pukat cincin di perairan bagian Timur Sulawesi Tenggara sejak tahun 20072013 berfluktuasi. Produksi maksimum terjadi pada tahun 2007 sebesar 6.763 ton, tahun 2010 sebesar 6.210 ton dan tahun 2013 sebesar 6.412 ton. Besarnya volume produksi pada tahun 2007, 2010 dan 2013 diikuti dengan besarnya poduktivitas ikan layang pada tahun tersebut.

Produktivitas hasil tangkapan menunjukkan bersarnya stok ikan yang dapat dimanfaatkan secara berkelanjutan. Hasibuan (1987) menjelaskan bahwa dinamika populasi stok ikan yang terdapat di perairan dapat dipengaruhi oleh kelahiran, kematian, imigrasi dan emigrasi. Sudradjat (2006) menjelaskan peningkatan dan penurunan stok ikan di perairan mempengaruhi stok populasi ikan. Peningkatan stok dipengaruhi oleh pertumbuhan dan rekruitmen. Penurunan 
stok dipengaruhi oleh mortalitas alami dan penangkapan. Produktivitas hasil tangkapan ikan layang dapat ditentukan dengan membandingkan besarnya produksi hasil tangkapan dengan besaranya upaya penangkapan yang dilakukan. Dalam penelitian ini upaya penangkapan yaitu banyaknya trip penangkapan per tahun dari tahun 2007-2013.

Fluktuasi produktivitas hasil
tangkapan ikan layang pada Gambar 3 dapat dijelaskan bahwa besarnya volume produktivitas dipengaruhi oleh besarnya upaya penangkapan yang dilakukan. Semakin tinggi upaya penangkapan (trip) maka volume produktivitas menjadi berkurang. Produktivitas pada tahun 2007 sebesar 2.60 ton/trip. Pada tahun 2008 mulai menurun sampai pada Tahun 2012. Produktivitas ikan layang meningkat kembali pada tahun 2013. Kondisi tersebut dapat dikatakan bahwa ikan layang melakukan rekruitmen di daerah penangkapan ikan dalam jangka waktu 5-6 tahun. Penurunan produktivitas dipengaruhi oleh penurunan volume produksi, dimana aktivitas penangkapan yang lebih besar dibandingkan dengan kemampuan rekruitmen stok ikan layang pada daerah penangkapan ikan di tahun tersebut. Sparre \& Venema (1999) menjelaskan bahwa rekruitmen stok ikan dapat terjadi apabila terdapat ikan yang dibiarkan menjadi dewasa, sebaliknya rekruitmen stok ikan di perairan tidak dapat terjadi apabila tidak ada ikan yang dibiarkan menjadi dewasa dan memijah. Bubun dan Mahmud (2015) menjelaskan bahwa ukuran panjang ikan yang tertangkap pada unit penangkapan pukat cincin (32\%) didominasi ikan layang dengan ukuran panjang 14$21 \mathrm{~cm}$. FAO (2015) menyebutkan bahwa ukuran panjang ikan layang pada saat pertama memijah yaitu $18 \mathrm{~cm}$ dengan panjang maksimal $35 \mathrm{~cm}$. Berdasarkan pernyataan tersebut, dapat dijelaskan bahwa ukuran panjang ikan mempengaruhi dinamika stok dan produktivitas ikan layang di perairan, sebab apabila ukuran panjang ikan mencapai ukuran panjang ikan dewasa, maka berat tubuh ikan akan bertambah. Kebijakan pemerintah dalam hal pengaturan waktu penangkapan perlu dilakukan, sehingga produktivitas ikan layang di daerah penangkapan ikan dapat dikendalikan secara lestari.

Pengelolaan sumberdaya perikanan dilakukan melalui kaidah-kaidah manajemen. Tujuannya adalah mampu mengatur produk yang dihasilkan dari ikan berlangsung secara terus-menerus dan dalam keadaan lestari serta populasi ikan tidak mengalami kepunahan dalam rangka pemanfaatan jangka panjang. Menyadari pentingnya menjaga kelestarian sumber daya perikanan adalah berarti pengelolaan sumberdaya perikanan dan kelautan diarahkan untuk mengacu kepada prinsip pemanfaatan dan pengelolaan sumber daya ikan yang bertanggung jawab (Nitja 2010).

Potensi maksimum lestari (MSY) dan jumlah tangkapan ikan layang yang diperbolehkan (JTB)

Pendekatan yang digunakan untuk tujuan pengelolaan perikanan dapat dilakukan dengan beberapa cara. Pertama, berbagai tujuan yang dimaksudkan untuk memperoleh hasil tangkapan tertentu secara fisik (jumlah berat) dari suatu perikanan. Versi yang paling umum adalah MSY (Maximum Sustainability Yield). Kedua, dengan masuknya pertimbangan ekonomi, memunculkan konsep MEY (Maximum Economic Yield) sebagai tujuan pengelolaan perikanan. Ketiga, sebagai reaksi terhadap kedua tujuan sebelumnya, maka tujuan pengelolaan adalah untuk memperoleh yield optimum. Konsep ini mencoba merangkum unsur-unsur ekonomi, biologi, sosial, dan politik ke dalam suatu fungsi obyektif pengelolaan sumberdaya perikanan, OSY (Optimum Sustainable Yield) (Widodo \& Suadi 2006).

Potensi maksimum lestari (MSY) merupakan suatu upaya penangkapan yang dapat menghasilkan hasil tangkapan maksimum secara lestari tanpa mempengaruhi produktivitas stok secara jangka panjang (Sparre \& Venema 1999). Penentuan Hasil tangkapan maksimum lestari dapat dilakukan dengan menggunakan model produksi surplus. Perhitungan model produksi surplus dalam penelitian ini berdasarkan nilai CPUE ikan layang dan upaya penangkapan selama tujuh tahun pada unit penangkapan pukat cincin. Jumlah tangkapan ikan layang yang diperbolehkan (JTB) dapat diketahui berdasarkan besarnya nilai MSY ikan layang.

Hasil penelitian diperoleh nilai MSY) ikan layang dari tahun 2007-2013 sebesar 5.747.61 ton/tahun. Gulland (1988) menyatakan bahwa MSY merupakan hasil tangkapan terbanyak berimbang yang dapat dipertahankan sepanjang masa pada suatu intensitas penangkapan tertentu 
yang mengakibatkan biomas sediaan ikan pada akhir suatu periode tertentu sama dengan sediaan biomas pada permulaan periode tertentu tersebut. Berdasarkan pernyataan tersebut dapat dijelaskan bahwa besarnya hasil tangkapan ikan yang dapat dimanfaatkan setiap tahun di perairan bagian timur Sulawesi Tenggara sebesar 5.747.61 ton.

Jumlah JTB menunjukkan besarnya produksi ikan layang yang dapat dimanfaatkan sebesar $80 \%$ dari potensi lestari ikan layang setiap tahun, dengan memperhatikan kelestarian spesies tersebut melalui rekruitmen di daerah penangkapan ikan (Setyohadi 2009). Nilai JTB ikan layang di perairan timur Sulawesi Tenggara sebanyak 4.598.09 ton/tahun. Nilai JTB tersebut dihitung berdasarkan asumsi maksimal pemanfaatan sebesar $80 \%$ dari nilai MSY. Berdasarkan nilai JTB yang diperoleh dapat dijelaskan bahwa apabila jumlah hasil tangkapan ikan yang dapat dimanfaatkan sebesar $80 \%$ dengan nilai JTN sebanyak 4.598.09 ton/ tahun, maka $20 \%$ atau sebanyak 1.149 .52 ton/tahun dari nilai MSY ikan layang dapat melakukan regenerasi di perairan bagian timur Sulawesi Tenggara. Alder et al. (2001) menjelaskan bahwa agar pemanfaatan sumberdaya perikanan dapat dilakukan secara berkelanjutan dan berwawasan lingkungan, maka perlu dilakukan upaya pengelolaan yang dapat menyeimbangkan tingkat pemanfaatannya. Pengelolaan yang dapat dilakukan di perairan bagian timur Sulawesi Tenggara agar potensi lestari ikan layang dapat ditingkatkan yaitu pengaturan musim penangkapan, jumlah armada penangkapan yang beroperasi dan ukuran mata jaring dapat disesuaikan dengan ukuran dewasa ikan yang menjadi target tangkapan.

Tabel 1. Ukuran dan jumlah unit penangkapan ikan pukat cincin Tahun 2007-2013

\begin{tabular}{cccccccc}
\hline $\begin{array}{c}\text { Armada kapal } \\
\text { motor (GP) }\end{array}$ & $\mathbf{2 0 0 7}$ & $\mathbf{2 0 0 8}$ & $\mathbf{2 0 0 9}$ & $\mathbf{2 0 1 0}$ & $\mathbf{2 0 1 1}$ & $\mathbf{2 0 1 2}$ & $\mathbf{2 0 1 3}$ \\
\cline { 2 - 8 } & $\mathbf{2 0 0}$ Tahun (Unit) & 17 & 63 & 24 & 12 & 8 \\
$5-10 \mathrm{GT}$ & 194 & 159 & 111 & 151 & 88 & 165 & 171 \\
$11-20 \mathrm{GT}$ & 10 & 15 & 9 & 9 & 10 & 15 & 17 \\
$21-30 \mathrm{GT}$ & 40 & 31 & 29 & 44 & 19 & 60 & 77 \\
$31-50 \mathrm{GT}$ & 4 & 3 & 1 & - & - & - & 1 \\
$>50 \mathrm{GT}$ & - & - & - & 1 & - & 2 & - \\
\hline Total & 281 & 225 & 167 & 268 & 141 & 254 & 274 \\
\hline
\end{tabular}

Sumber : Data statistik PPS Kendari Tahun 2007-2013

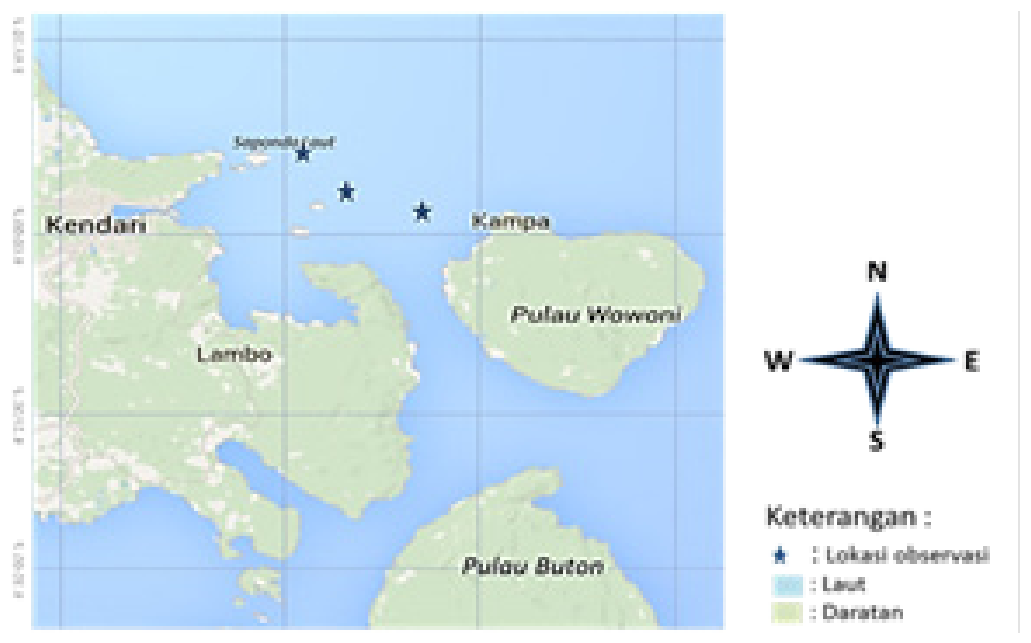

Gambar 1. Lokasi observasi daerah penangkapan ikan pukat cincin 


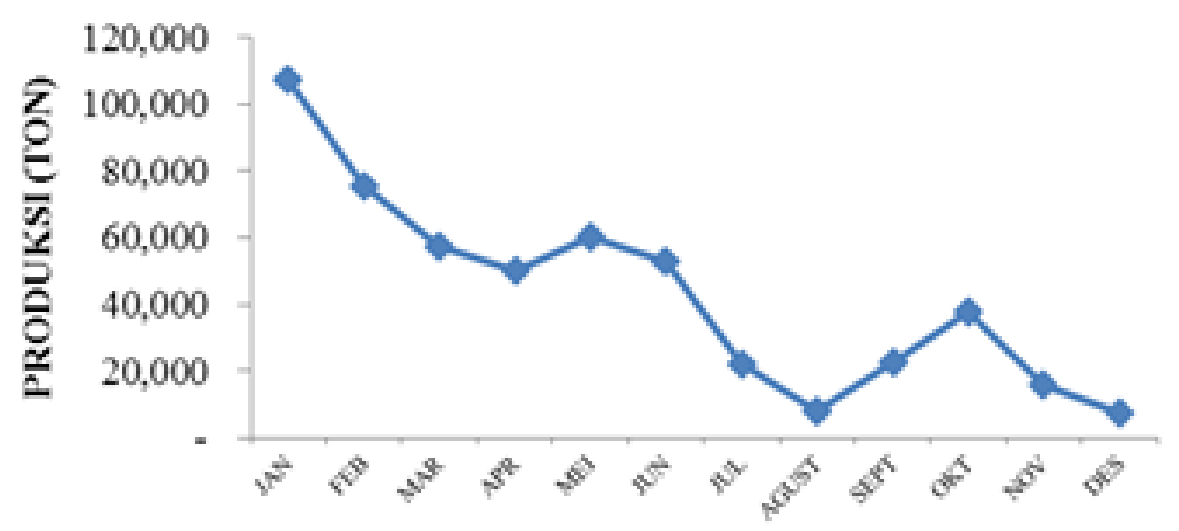

BULAN (Tahun 2007 - 2013)

Gambar 2. Musim penangkapan ikan layang berdasarkan volume produksi

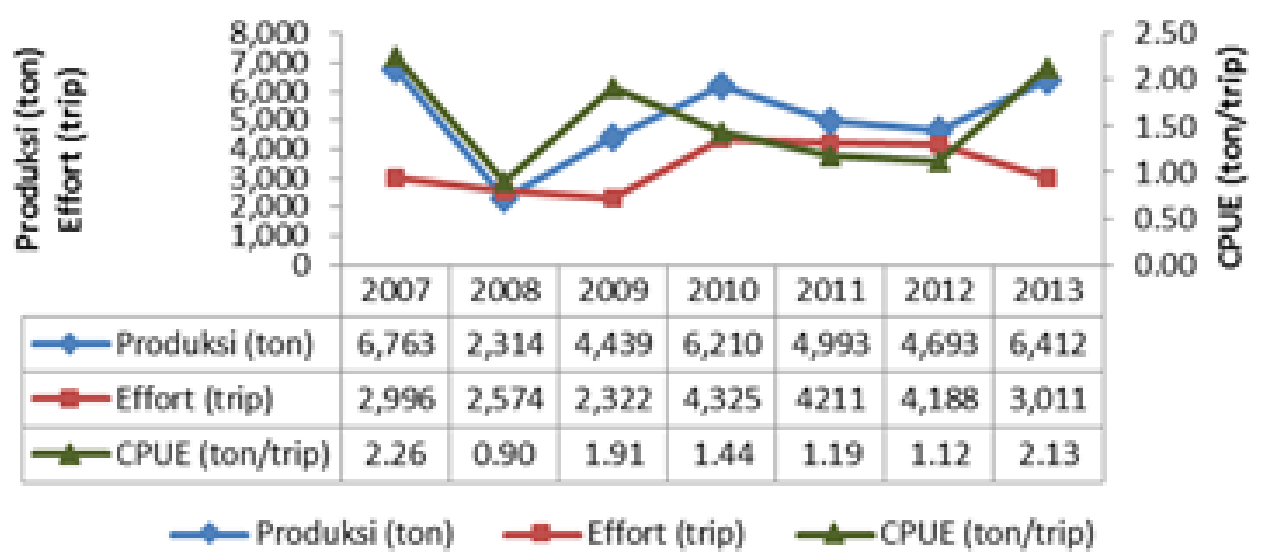

Gambar 3. Produksi upaya penangkapan dan produktivitas hasil tangkapan ikan

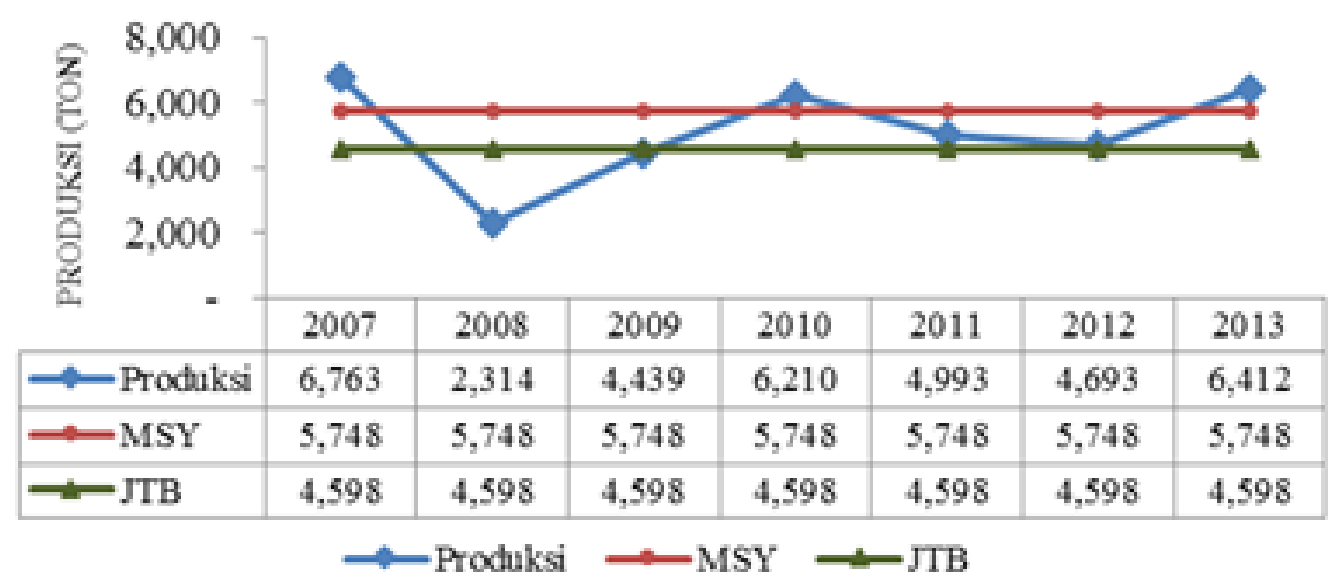

Gambar 4. Produksi, MSY dan JTB ikan layang 


\section{KESIMPULAN DAN SARAN}

\section{Kesimpulan}

Hasil penelitian mengenai potensi lestari ikan layang (Decapterus spp) berdasarkan hasil tangkapan pukat cincin di perairan timur laut Sulawesi Tenggara adalah potensi maksimum lestari (MSY) ikan layang mencapai 5.747.61 ton/tahun, dan jumlah tangkapan ikan layang yang diperbolehkan (JTB) sebesar 4.598 ton/ tahun.

\section{Saran}

Ikan layang merupakan salah satu spesies ikan pelagis kecil yang mempunyai nilai ekonomi penting. Berdasarkan hasil penelitian diperoleh informasi mengenai potensi lestari ikan layang dan jumlah hasil tangkapan yang diperbolehkan. Hal ini perlu mendapat perhatian pemerintah sebagai pembuat kebijakan, agar dapat membuat aturan dalam pemanfaatan sumberdaya ikan layang sehubungan dengan upaya penangkapan (jumlah armada dan waktu penangkapan), sehingga pemanfaatan sumberdaya ikan layang dapat dilakukan secara berkelanjutan. Penelitian mengenai tingkat pemanfaatan ikan layang perlu dilakukan sehingga dapat diketahui seberapa besar pemanfaatan ikan layang di perairan timur Sulawesi Tenggara.

\section{DAFTAR PUSTAKA}

[FAO] Food and Agriculture Organization of The United Nations. 2015. Fish base [internet]. http://www.fao.org.

[KKP] Kementerian Kelautan Perikanan. 2011. Peraturan Menteri Kelautan dan Perikanan Republik Indonesia Nomor 02 Tahun 2011 tentang Jalur Penangkapan Ikan dan Penempatan Alat Penangkapan Ikan dan Alat Bantu Penangkapan Ikan di Wilayah Pengelolaan Perikanan Negara Republik Indonesia. Jakarta: KKP.

[PPS] Pelabuhan Perikanan Samudera Kendari. 2012. Laporan Statistik Tahunan Pelabuhan Perikanan Samudera Kendari. Kendari: Kementrian Kelautan dan Perikanan (KKP)-Direktorat Jenderal Perikanan Tangkap.

[PPS] Pelabuhan Perikanan Samudera Kendari. 2013. Laporan Statistik Tahunan Pelabuhan Perikanan
Samudera Kendari. Kendari: Kementrian Kelautan dan Perikanan (KKP)-Direktorat Jenderal Perikanan Tangkap.

[PPS] Pelabuhan Perikanan Samudera Kendari. 2007. Laporan Statistik Tahunan Pelabuhan Perikanan Samudera Kendari. Kendari: Kementrian Kelautan dan Perikanan (KKP)-Direktorat Jenderal Perikanan Tangkap.

[PPS] Pelabuhan perikanan Samudera Kendari. 2008. Laporan Statistik Tahunan Pelabuhan Perikanan Samudera Kendari. Kendari (ID). Kementrian Kelautan dan Perikanan (KKP)-Direktorat Jenderal Perikanan Tangkap.

[PPS] Pelabuhan perikanan Samudera Kendari. 2009. Laporan Statistik Tahunan Pelabuhan Perikanan Samudera Kendari. Kendari (ID). Kementrian Kelautan dan Perikanan (KKP)-Direktorat Jenderal Perikanan Tangkap.

[PPS] Pelabuhan Perikanan Samudera Kendari. 2010. Laporan Statistik Tahunan Pelabuhan Perikanan Samudera Kendari. Kendari (ID). Kementrian Kelautan dan Perikanan (KKP)-Direktorat Jenderal Perikanan Tangkap.

[PPS] Pelabuhan Perikanan Samudera Kendari. 2011. Laporan Statistik Tahunan Pelabuhan Perikanan Samudera Kendari. Kendari: Kementrian Kelautan dan Perikanan (KKP)-Direktorat Jenderal Perikanan Tangkap.

Alder J, Pritcher TJ, Preikshot D, Ferriss B, Kaschner K. 2001. How Good is Good?: A Rapid Appraisal Technique for Evaluation of the Sustainability Status of Fisheries of the North Atlantic. Vancouver, Canada: University of British Columbia.

Bubun RL, Mahmud A. 2015. Keanekaragaman hasil tangkapan ikan pukat cicin menggunakan light fishing hubungannya dengan teknologi penangkapan ikan ramah lingkungan. Marine Fisheries (siap terbit).

Gulland JA. 1983. Fish Stock Assesment. A Manual of Basic Methods. New York: John Wiley and Sons. Inc.

Hasibuan KM. 1987. Permodelan Matematika di dalam Biologi Populasi. Bogor: Institut Pertanian Bogor.

Nontji A. 2002. Laut Nusantara. Jakarta 


\section{:Djambatan}

Nuitja INS. 2010. Manajemen Sumberdaya Perikanan. Bogor: IPB Press.

Simbolon D. 2011. Bioekologi dan Dinamika Daerah Penangkapan Ikan. Bogor: Institut Pertanian Bogor.

Sparre P, Venema SC. 1999. Introduksi Pengkajian Stok Ikan Tropis. Roma: FAO. Diterjemahkan oleh Pusat Penelitian dan Pengembangan Perikanan. Jakarta: Badan Litbang Pertanian.

Sudradjat A. 2006. Studi pertumbuhan, mortalitas dan tingkat eksploitasi ikan selar kuning, Selaroides leptolepis (Cuvier dan Valenciennes) di Perairan Pulau Bintan, Riau. Journal of Fisheries Science. 7(2):223-228.

Widodo J, Suadi. 2006. Pengelolaan Sumberdaya Perikanan Laut. Yogyakarta: Gadja Mada University Press.

Setyohadi D. 2009. Studi potensi dan dinamika stok ikan lemuru (Sardinella lemuru) di Selat Bali serta alternatif penangkapannya. Journal of Fisheries Sciences. 11(1):78-86. 